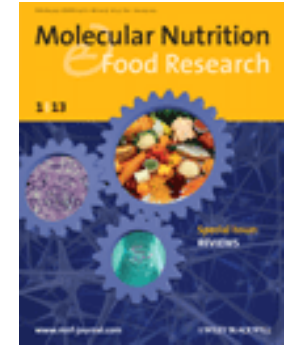

\title{
Circulating dendritic cells from celiac disease patients display a gut-homing profile and are differentially modulated by different gliadin-derived peptides
}

\begin{tabular}{|c|c|}
\hline Journal: & Molecular Nutrition and Food Research \\
\hline Manuscript ID & mnfr.201900989.R1 \\
\hline Wiley - Manuscript type: & Research Article \\
\hline $\begin{array}{r}\text { Date Submitted by the } \\
\text { Author: }\end{array}$ & $n / a$ \\
\hline Complete List of Authors: & $\begin{array}{l}\text { Escudero Hernández, Celia; Universidad de Valladolid Facultad de } \\
\text { Medicina, Mucosal Immunology Laboratory; Instituto de Biología y } \\
\text { Genética Molecular, Mucosal Immunology Laboratory } \\
\text { Martín, Álvaro; Instituto de Biología y Genética Molecular, Flow } \\
\text { Cytometry facility } \\
\text { de Pedro Andrés, Rodrigo; Universidad de Valladolid Facultad de } \\
\text { Medicina, Mucosal Immunology Laboratory; Instituto de Biología y } \\
\text { Genética Molecular, Mucosal Immunology Laboratory } \\
\text { Fernández-Salazar, Luis; Hospital Clínico Universitario de Valladolid, } \\
\text { Digestive Disease Unit } \\
\text { Garrote, José; Hospital Universitario Rio Hortega, Laboratory of } \\
\text { Molecular Genetics; Universidad de Valladolid Facultad de Medicina, } \\
\text { Mucosal Immunology Laboratory } \\
\text { Bernardo, David; Universidad de Valladolid Facultad de Medicina, } \\
\text { Mucosal Immunology Laboratory; Instituto de Biología y Genética } \\
\text { Molecular, Mucosal Immunology Laboratory } \\
\text { Arranz, Eduardo; Universidad de Valladolid Facultad de Medicina, } \\
\text { Mucosal Immunology Laboratory; Instituto de Biología y Genética } \\
\text { Molecular, Mucosal Immunology Laboratory }\end{array}$ \\
\hline Keywords: & Antigen presentation, autoimmune disease, gliadin, monocyte, $T$ cell \\
\hline
\end{tabular}

\section{SCHOLARONE ${ }^{\mathrm{m}}$ Manuscripts}


1 TITLE: Circulating dendritic cells from celiac disease patients display a gut-homing profile and

2 are differentially modulated by different gliadin-derived peptides

3 AUTHORS: Celia Escudero-Hernández ${ }^{1, *}$, Álvaro Martín ${ }^{2}$, Rodrigo de Pedro Andrés ${ }^{1}$, Luis 4 Fernández-Salazar ${ }^{3}$, José Antonio Garrote ${ }^{1,4}$, David Bernardo $1, \$$, Eduardo Arranz ${ }^{1, \$}$

\section{AFFILIATIONS:}

61 Mucosal Immunology Laboratory, Instituto de Biología y Genética Molecular (IBGM), 7 University of Valladolid-CSIC, C/ Sanz y Forés 3, 47003 Valladolid, Spain.

$8{ }^{2}$ Flow Cytometry facility. Instituto de Biología y Genética Molecular (IBGM), University of 9 Valladolid-CSIC, C/ Sanz y Forés 3, 47003 Valladolid, Spain.

$10{ }^{3}$ Digestive Disease Unit. Hospital Clínico Universitario de Valladolid. Avda Ramón y Cajal 3, 1147003 ,Valladolid, Spain.

124 Laboratory of Molecular Genetics, Hospital Universitario Rio Hortega, C/ Dulzaina 2, 47012 13 Valladolid, Spain.

14 \$Both authors had same contribution as senior authors of the study.

$15{ }^{*}$ Current address: Department of Clinical and Experimental Medicine (IKE), Linköping 16 University, Linköping, Sweden

\section{CORRESPONDING AUTHORS:}

- Celia Escudero-Hernández. Department of Clinical and Experimental Medicine (IKE), Ingång 68, Plan 13, US campus, Linköping University, s-581 83, Linköping, Sweden. E-mail: celia.escher@gmail.com / celia.escudero-hernandez@liu.se

- Eduardo Arranz. Mucosal Immunology Laboratory, Instituto de Biología y Genética Molecular (IBGM), University of Valladolid-CSIC, C/ Sanz y Forés 3, 47003 Valladolid, Spain. E-mail: earranz@uva.es

ABBREVIATIONS: c, conventional; CCR, C-C motif chemokine receptor; CeD, celiac disease; cDC, conventional dendritic cell; cl, classical; CLA, cutaneous leukocyte-associated antigen 
26 receptor; DC, dendritic cell; GFD, gluten-free diet; int., intermediate; MHC, major 27 histocompatibility complex; Mo, monocyte; MoDC, monocyte-derived dendritic cell; p, peptide; 28 PBMC, peripheral blood mononuclear cell; pDC, plasmacytoid dendritic cell; TGF, transforming 29 growth factor; Th, T helper cell; TNF, tumor necrosis factor.

30 KEYWORDS: Antigen presentation, autoimmune disease, gliadin, monocyte, T cell 


\section{ABSTRACT}

\section{Scope}

Circulating dendritic cell (DC) and monocyte subsets contribute to the pool of intestinal DC and macrophages in celiac disease (CeD), an autoimmune gut disorder triggered by dietary gluten. Here, we aimed to characterize these circulating subsets in CeD and assess the effect of different gliadin-derived peptides on conventional DC (CDC).

\section{Methods and results}

Flow cytometry profiling of peripheral blood mononuclear cells revealed a slight decrease in the proportion of plasmacytoid and type $1 \mathrm{cDC}$ in gluten-free diet (GFD)-treated CeD patients. In comparison to healthy donors, DC and monocyte subsets from active and GFD-treated CeD patients displayed an increased gut-homing profile. Type 2 cDC (cDC2) were sorted and stimulated with the gliadin-derived peptides 8-mer, 19-mer and 33-mer. All peptides induced cDC2 maturation, although the profile was different. While peptide 8-mer induced a Th1/Th17 pro-inflammatory cytokine profile in active CeD patients, cDC2 primed with peptide 33-mer displayed a higher capacity to promote gut-homing CCR9 ${ }^{+}$expression onto autologous Tcells.

\section{Conclusion}

Distinct gliadin-derived peptides elicit different effects on cDC2 phenotype and function. This effect is compatible with a model where diverse gliadin peptides might cooperate to promote full cDC2 activation and the subsequent T-cell response in genetically predisposed individuals. 


\section{Introduction}

Celiac disease (CeD) is an increasingly common food sensitivity and gastrointestinal autoimmune disorder of the small intestine, affecting approximately $1 \%$ of the population. ${ }^{[1]}$ It is triggered in genetically predisposed individuals, carrying the human leukocyte antigen (HLA)-DQ2 and/or HLA-DQ8 molecules, following gluten consumption. ${ }^{[2]}$ Currently, the only reliable treatment is a lifelong strict gluten-free diet (GFD) after which all clinical symptoms usually disappear. ${ }^{[1 a, 3]}$

Gluten is a complex mixture of seed storage proteins found in wheat, rye, barley and certain oat grains that are highly resistant to proteolytic processes occurring during digestion. ${ }^{[4]}$ Among these resistant fractions, $\alpha$ - and $\omega$-gliadins from wheat's gluten contain the most immunodominant peptides for CeD patients. The most studied gliadin peptides typically include peptide (p)31-49 (PGQQQPFPPQQPYPQPQPF, also known as 19-mer), which generates an innate immune response in intestinal epithelial cells and intraepithelial lymphocytes; and p5688 (LQLQPFPQPQLPYPQPQLPYPQPQLPYPQPQPF, also known as 33-mer), that mediates an adaptive immune response. ${ }^{[5]}$ However, the latest technical improvements have allowed the identification of new gliadin-derived peptides that can be recognized by T-cells. ${ }^{[6]}$ This is the case of a small eight residue peptide, 8-mer (FPLQPQQP), which our group recovered from a gluten degrading band found after a duodenal extract from a CeD patient was incubated with gliadin by zymography. ${ }^{[7]}$ However, the mechanism of action of this novel 8-mer peptide remains unknown.

Dendritic cells (DC), the most potent antigen presenting cells, determine the antigen-specific immune outcome, i.e. pro-inflammatory or tolerogenic response. ${ }^{[8]}$ In the intestinal mucosa, DC control immune tolerance towards nutrients and commensals by promoting regulatory T-cell differentiation and $\mathrm{B}$-cell $\lg \mathrm{A}$ secretion via $\alpha \mathrm{V} \beta 8$ integrin and retinaldehyde dehydrogenase type (RALDH) 2 enzyme, respectively. ${ }^{[9]} \mathrm{DC}$ also imprint homing properties over the cells that they stimulate by inducing small bowel-homing C-C motif chemokine receptor (CCR) 9 and 
gut-homing $\alpha 4 \beta 7$ integrin expression, ${ }^{[10]}$ hence restricting immune responses to the gastrointestinal compartment. ${ }^{[11]}$ In addition, DC can trigger immune responses against invading pathogens in the gut. ${ }^{[12]}$ Consequently, changes in this delicate balance between immunity and tolerance are related to progression of autoimmune diseases, including CeD. ${ }^{[2 b}$, 12d, 13] Intestinal macrophages also maintain the mechanisms of immune homeostasis in health, although they can also exacerbate immune responses in the presence of inflammation. ${ }^{[14]}$ Their main role in the gut is the clearance of microbes that cross the epithelial barrier in a CX3CR1dependent manner. ${ }^{[15]}$ Thus, intestinal macrophages are abundant in the epithelial layer of the mucosa and contribute to the homeostasis and replacement of epithelial cells. To do so, macrophages remodel the extracellular matrix by producing metalloproteinases and tumor necrosis factor (TNF)- $\alpha .^{[16]}$ They also contribute to recruit monocytes, maintain and expand Th17 cells, and co-stimulate antigen-specific $T$ cells in situ. ${ }^{[14 \mathrm{~d}]}$ The last members of the mononuclear phagocyte system are monocytes, considered the precursors of intestinal macrophages. ${ }^{[13,17]}$

Recently, Guilliams et al. proposed a homogeneous system to classify all mononuclear phagocyte cells. Human DC are divided into plasmacytoid DCs (pDCs: CD11c-CD123+), which produce large amounts of type I interferons; and myeloid, classical or conventional DC (cDC: CD11 $\mathrm{c}^{+}$), which perform antigen presentation. $\mathrm{CDC}$ can be further divided into type $1(\mathrm{cDC} 1$ : $\mathrm{CD} 141^{+}, \mathrm{C}-\mathrm{X}-\mathrm{C}$ motif chemokine receptor $\left.(\mathrm{CXCR}) 1^{+}\right)$, which present exogenous antigens on MHC-I molecules; and type $2\left(\mathrm{CDC} 2: \mathrm{CD} 1 \mathrm{C}^{+}\right.$, signal regulatory protein $\left.(\mathrm{SIRP}) \alpha^{+}\right)$, which present antigens in the classical major histocompatibility complex (MHC)-II molecules. ${ }^{[18]}$ On the other side, macrophages are self-maintaining cells derived from embryonic progenitors and are classified according to their particular location or historical name. ${ }^{[18 a]}$ However, under inflammatory conditions, mucosal macrophages are originated from circulating monocytes, ${ }^{[19]}$ which are divided into classical $\left(\mathrm{CD} 14^{+} \mathrm{CD} 16^{-}\right)$, intermediate $\left(\mathrm{CD} 14^{+} \mathrm{CD} 16^{+}\right)$, and non-classical $\left(\mathrm{CD} 14-\mathrm{CD} 16^{+}\right)$monocytes. ${ }^{[13,17]}$ 
105 The celiac mucosa is characterized by low levels of pDCs and regulatory CD103+ DCs, 106 together with low expression of interferon (IFN)- $\alpha^{[20]}$ On the contrary, active cDCs and 107 macrophages accumulate in the inflamed tissue, which leads to the activation of gluten-specific 108 T-cells. ${ }^{[20 \mathrm{~b}, 21]}$ These changes, however, are not restricted to the intestinal mucosa as active 109 CeD patients also display low numbers of circulating cDC. ${ }^{[22]}$ Nevertheless, not much effort 110 has been focused on characterizing circulating $\mathrm{CDC}$ and monocyte/macrophage populations 111 in depth in CeD. In addition, most studies have focused on the characterization of monocyte112 derived $\mathrm{DC}(\mathrm{MoDC})$ to describe antigen presentation and immune responses in CeD. ${ }^{[23]}$ 113 However, MoDC do not truly resemble the properties of human cDC2. ${ }^{[24]}$ Thus, the specific 114 effect that different gliadin-derived peptides may elicit over bona fide cDC phenotype and 115 function remains to be analyzed.

116 In order to address these limitations, we provide a comprehensive characterization of human 117 circulating DC and monocyte subsets in healthy controls and CeD subjects. Moreover, we also 118 unravel the effects that different gliadin peptides (8-mer, 19-mer and 33-mer) induce on human 119 cDC2 phenotype and function, describing how distinct peptides activate cDC2 in different 120 manners. 


\section{Experimental section}

122

\subsection{Study population}

Blood samples $(50 \mathrm{~mL})$ from adult $\mathrm{CeD}$ patients and healthy volunteers were obtained in heparin-litium tubes from the Digestive Disease Unit at "Hospital Clínico Universitario" (Valladolid, Spain). CeD was diagnosed following the current diagnosis guidelines, including clinical history, genetics, serology, upper gastroscopy and small intestinal biopsy (MarshOberhuber classification). ${ }^{[25]}$ In total, 5 patients with active CeD and 11 GFD-treated CeD patients were enrolled. Additionally, 9 healthy donors with no known autoimmune diseases, inflammation or autoimmune malignancies were recruited as controls. Detailed patient characteristics can be found in table 1. Written informed consent was obtained from all subjects following approval by the local ethics committee (FO-P-07-03). All subjects were of European ancestry.

\subsection{Dendritic and T-cell isolation}

Peripheral blood mononuclear cells (PBMCs) were isolated by density gradient centrifugation using $1.077 \mathrm{~g} / \mathrm{mL}$ Ficoll (BioChrom, Berlin, Germany), and further washed with phosphatebuffered solution (PBS) (Lonza, Verviers, Belgium) supplemented with $2 \%$ fetal bovine serum (FBS, Invitrogen, Carlsbad, CA, USA). Five million PBMCs were kept aside for flow cytometry analysis of fresh circulating DC and monocyte subsets. CDC2 cells were magnetically isolated from total PBMCs with CD1C (BDCA-1)+ dendritic cell isolation kit for human samples (Miltenyi Biotech, Bergisch Gladbach, Germany), following the manufacturer's instructions. Briefly, PBMCs were firstly incubated with Fc Receptor blocking reagent and anti-CD19 microbeads in order to deplete B-cells. In a second magnetic isolation round with anti-CD1c-biotin microbeads, CDC2 and the remaining non-labelled cells were collected in separate tubes. An average purity of $91.30 \pm 8.98 \% \mathrm{cDC} 2$ was confirmed by flow cytometry (supplementary figure 1). cDC2 were used for in vitro stimulation with gliadin-derived peptides (see below), while the B-cell and cDC2 depleted cell fraction was used to isolate naïve T-cells (CD3 $\left.{ }^{+} \mathrm{CD} 4^{+} \mathrm{CD} 45 \mathrm{R} \mathrm{A}^{+}\right)$ 
147 by cell sorting in a FACS Aria instrument (Becton Dickinson, Franklin Lakes, NJ, USA). Purity 148 of sorted naïve T-cells was higher than $95 \%$ in all cases. Details of all the antibodies used can 149 be found in Supplementary Table 1.

\subsection{In vitro assays and dosage information}

151 A total of 70,000 viable cDC2 cells were seeded in complete medium (RPMI 1640 medium 152 (Lonza) supplemented with 10\% FBS (Invitrogen), 1\% L-glutamine (Sigma-Aldrich, San Luis, 153 MO, USA) and 1\% penicillin-streptomycin (Sigma-Aldrich)). Cell viability was assessed with 154 TrypanBlue (Thermofisher Scientific). The gliadin-derived peptides 8-mer, 19-mer, and 33-mer 155 were added at a concentration of $100 \mu \mathrm{M}$ to stimulate $\mathrm{cDC} 2$ for $18 \mathrm{~h}\left(37^{\circ} \mathrm{C}, 5 \% \mathrm{CO}_{2}\right)$. All the 156 peptides were LPS-free and were synthetized by Biomedal S.L. (Sevilla, Spain) at a purity level 157 of $98 \%$. Unstimulated cells were kept in culture in resting conditions as negative controls. The 158 dose was selected on the basis of previous studies on in vitro challenged cell lines with gliadin159 derived peptides19-mer and 33-mer. ${ }^{[26]}$ Following culture, cDC2 were recovered with TrypLE 160 Express (ThermoFisher Scientific, Waltham, MA, USA). Cell viability - assessed by flow 161 cytometry - after culture was over $80 \%$ in all cases with no changes between different patient 162 groups or culture conditions (supplementary figure 2).

163 A total of 10,000 stimulated, viable cDC2 were seeded together with sorted naïve T-cells in a $1641: 10$ proportion for 5 days in the supplemented RPMI 1640 medium described above $\left(37^{\circ} \mathrm{C}\right.$, $1655 \% \mathrm{CO}_{2}$ ). Naïve T-cells had been previously labelled with carboxyfluorescein succinimidyl 166 ester (CFSE, Invitrogen), following the manufacturer's instructions. In all cases, cell viability was assessed on cells before culture using TrypanBlue.

\subsection{Flow cytometry}

169 PBMCs were used to characterize monocyte and DC subset homing profile (C-C chemokine 170 receptor (CCR) 9; $\beta 7$ integrin, and cutaneous leukocyte-associated antigen receptor (CLA)). 171 After in vitro stimulation with gliadin-derived peptides, CDC2 were also labelled with 
172 LIVE/DEAD fixable yellow dead cell stain kit (Invitrogen, following the manufacturer's

173 instructions), and characterized for the expression of maturation (CD40, CD80, CD83, CD86,

174 HLA-DR) and migration (CCR9, $\beta 7, C L A)$ markers. Isolated naïve T-cells co-cultured with 175 cDC2 were labelled with LIVE/DEAD fixable yellow dead cell stain kit, and used to assess the 176 expression of migration markers (CCR9, $\beta 7$, CLA) and cytokine production (IL-10, IFN- $\gamma$, IL177 17A). Antibody details can be found in Supplementary Table 1. In all cases, cells were stained 178 for $30 \mathrm{~min}$ in the dark at $4^{\circ} \mathrm{C}$ and washed with FACS buffer (phosphate saline buffer with $1 \%$ 179 FBS). Intracellular cytokine staining was performed on T-cells after fixation with $2 \%$ paraformaldehyde (PFA, Sigma-Aldrich) in PBS, and using a freshly home-made $0.1 \%$ saponin

181 (Sigma-Aldrich) solution in FACS buffer for $30 \mathrm{~min}$ in the dark at room temperature with 182 frequent agitation. For T-cell analysis, fluorochromes used for naïve T-cell sorting were 183 avoided. Cells were always fixed in $2 \%$ PFA as mentioned above following antibody staining. 184 Fluorescence minus one (FMO) samples were used as internal controls to set positive and 185 negative gatings. All flow cytometry assays were run in a Gallios flow cytometer and analyzed 186 with Kaluza v2.1.1 software (all from Beckman Coulter Inc., Brea, CA, USA) and Fowjo v10.6.1 187 (BD, Franklin Lakes, NJ, USA).

\subsection{Expression analyses}

Total RNA was extracted from peptide-stimulated cDC2 with RNeasy mini kit following manufacturer's instructions (QIAGEN, Hilden, Germany). RNA was quantified in NanoDrop ND-1000, and retrotranscribed with High Capacity cDNA Reverse Transcription Kit (all from

192 ThermoFisher Scientific). Complementary DNA was amplified using iTaq Universal SYBR 193 Green Supermix or iTaq Universal Probes Supermix (all from BioRad, Hercules, CA, USA). 194 Specific primers were designed with Primer Blast from the National Center for Biotechnology 195 Information, NCBI (Supplementary table 2). ${ }^{[27]}$ A customized Universal Probe Library (UPL) 196 was obtained for IL6 (Roche Pharmaceuticals, Basel, Switzerland). Quantitative analysis was carried out in a LightCycler480 (Roche Pharmaceuticals) using the relative quantification $-\Delta \Delta \mathrm{Ct}$ 
199 housekeeping gene. Non-stimulated cells from each CeD patient or healthy volunteer were

200 used as a control, and average population-based values were used to obtain $-\Delta \Delta$ Ct values.

\section{$201 \quad 2.6$ Statistical analysis}

202 Flow cytometry data was analyzed with ANOVA's analysis of variance to contrast data between 203 different patient groups, and two-tailed paired Student's t-test to contrast data from different 204 conditions within the same patient sample (i.e. treated vs untreated/control cells). Quantitative 205 PCR data were analyzed with Student's unpaired t-test. All statistical tests were performed in 206 SPSS software v15.0 (IBM, Armonk, NY, USA), and data was represented with GraphPad 207 Prism software v8.0.1 (GraphPad, San Diego, CA, USA). Results were considered significant 208 if $p$-value was less than 0.05. 


\section{Results}

\subsection{Circulating DC and monocyte subsets display a gut-homing profile in CeD patients}

211 The contribution of circulating DC and monocyte subsets in CeD is not fully understood. 212 However, it has been suggested that a mucosal immune cell misbalance is mirrored in the 213 circulatory system. ${ }^{[22]}$ We therefore characterized the proportion and homing profile of both cell 214 types in peripheral blood samples from active and GFD-treated CeD patients, as well as 215 healthy donors. All cells were identified within singlet viable PBMCs as pDC (HLA-DR $\left.{ }^{+} C D 123^{+}\right)$,

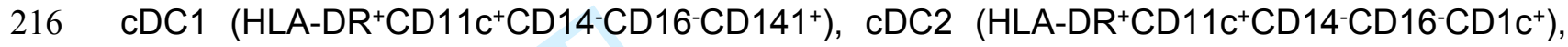
217 classical monocytes (HLA-DR $\left.{ }^{+} \mathrm{CD} 11 \mathrm{c}^{+} \mathrm{CD} 14^{+} \mathrm{CD} 16-\right)$, non-classical monocytes (HLA$218 \mathrm{DR}^{+} \mathrm{CD} 11 \mathrm{c}^{+} \mathrm{CD} 14-\mathrm{CD}^{+} 6^{+}$), and intermediate monocytes (HLA-DR ${ }^{+} \mathrm{CD} 11 \mathrm{c}^{+} \mathrm{CD} 14^{+} \mathrm{CD} 16^{+}$)

219 (Figure 1A). Although not statistically significant, GFD-treated CeD (but not patients with active disease) displayed a lower proportion of circulating $\mathrm{pDC}$ and $\mathrm{CDC} 1$ than healthy controls

221 (Figure 1B-C). The proportion of circulating CDC2 and monocyte subsets was not altered in any case (Figure 1D-G). However, due to the low number of active CeD patients recruited, we are aware that these results should be considered carefully.

After identifying the different cell types, we next studied their homing profile by assessing the expression of the CCR9 and $\beta 7$ integrin gut-homing markers, and the CLA skin-homing marker (Figure 2A). CeD-circulating DC subsets mainly differed in CCR9 and CLA expression from healthy individuals (Figure 2B-D). In particular, pDC from GFD-treated CeD patients seemed to display higher levels of CCR9 and lower levels of CLA (Figure 2B). Similarly, CDC1 followed

229 the same expression pattern trend as PDC, with slightly increased levels of CCR9 and lower 230 levels of CLA in both active $\mathrm{CeD}$ and GFD-treated CeD patients (Figure 2C). On the other 231 hand, CDC2 had higher CCR9 and lower average expression of CLA only in active CeD 232 patients (Figure 2D). In contrast with DC, all monocyte subsets favored a higher expression of 233 the $\beta 7$ integrin in patients with active inflammation, but not in those under a GFD (Figure 2E$234 \mathrm{G})$. Indeed, the expression of $\beta 7$ on classical monocytes from GFD-treated CeD patients was 
235 even lower than in healthy controls (Figure 2E). In summary, these results demonstrate that

236 antigen presenting cell subsets might be altered in active $\mathrm{CeD}$ as they display a preferential

237 gut-homing profile during mucosal inflammation. However, this hypothesis deserves further

238 analysis due to the low number of active CeD patients enrolled in this study.

\subsection{Gliadin-peptides induce maturation on cDC2 from GFD-treated CeD patients}

$240 \mathrm{cDC}$ have been considered as central drivers of CeD pathogenesis. ${ }^{[20 b, 20 c, 29]}$ Given their

241 increased gut-homing capacity displayed in CeD patients, ${ }^{[20 \mathrm{~b}, 30]}$ we next decided to 242 characterize them. Since cDC1 proportion was scarce (Figure 1B), we focused on cDC2 to 243 study the effect that several gliadin-derived peptides elicited over DC phenotype and function.

244 The classical immunogenic peptide 33-mer increased the expression of CD40 and CD80 in 245 cDC2 from healthy controls, while it increased the expression of CD80, CD83, and CD86 in 246 cDC2 from GFD-treated CeD patients (Figure 3A-D). On the other hand, cDC2 from GFD247 treated CeD patients responded to peptide 8-mer by increasing the expression of CD40 and 248 CD80; and to peptide 19-mer, by increasing CD80 and CD86 (Figure 3A-D). Of note, none of the peptides changed the expression of the activation markers on cDC2 enriched from patients with active disease (Figure 3A-D). Homing marker expression (CCR9, $\beta 7$ integrin and CLA) on cDC2 was not affected by these peptides in any of the three studied groups (supplementary

252 figure 3 ). Altogether, these results suggest that gliadin-derived peptides induce cDC2 253 activation, being peptide 33-mer the most immunodominant peptide.

\subsection{Peptide 8-mer induces a Th1/Th17 cytokine profile on cDC2 from active CeD patients}

255 Given that the gliadin-derived peptides induced cDC2 activation, we next addressed whether 256 this was also followed with a differential cytokine profile. IL4 and IL12A mRNA were not 257 detected in any case, so they were excluded from the analysis (data not shown). Peptide 33258 mer increased the expression of IL6 and IL23A in healthy controls, whereas only the 259 expression of IL6 was increased in active CeD patients (Figure 4A-B). On cDC2 from GFD- 
260 treated CeD patients, however, 33-mer decreased the expression of IFNG, IL10 and IL23A

261 (Figure 4C). On the contrary, peptide 8-mer increased the expression of IFNG, IL6 and IL23A on cDC2 from patients with active $\mathrm{CeD}$ (Figure 4B), and decreased the expression of IFNG and IL10 in GFD-treated CeD patients (Figure 4C). However, 8-mer did not significantly changed the expression of any of the analyzed cytokines on cDC2 from healthy controls (Figure 4A). Finally, peptide 19-mer increased the expression of IFNG and decreased the expression of IL23A in CDC2 from active CeD patients, whereas it decreased the expression of IL6, IL10 and IL23A in GFD-treated CeD patients (Figure 4B-C). Taken together, the cytokine expression profile induced on gliadin-peptide stimulated CDC2 suggests a proinflammatory response towards a Th1/Th17 profile in active CeD patients, which was more prominent when the cells had been primed with peptide 8-mer. On the other hand, gliadinpeptide stimulated CDC2 from GFD-treated CeD patients showed a decreased expression of 272 proinflammatory cytokines, suggesting the need of additional stimuli to trigger the immune 273 response to gluten.

\subsection{Naïve T-cells increase CCR9 expression after co-culture with 33-mer primed} autologous CDC2

276 Since these three gliadin-derived peptides induced changes on cDC2 activation markers

277 (mainly peptide 33-mer) and cytokine profile (prominently peptide 8-mer), we next addressed 278 whether this was resembled on a differential effect over autologous naïve T-cells.

279 cDC2 did not alter T-cell proliferation -assessed by CFSE dilution on T-cells-, in any of the 280 study groups when compared to non-stimulated cDC2 (data not shown). Moreover, despite the 281 effects of the gliadin-derived peptides on cDC2 activation and cytokine expression, no changes 282 were observed in the cytokine profile of stimulated T-cells (CFSE ${ }^{\text {low}}$ ), neither from healthy 283 controls nor from CeD patients (Figure 5A, B, C). However, 33-mer-primed cDC2 from all study 284 groups (healthy controls, active CeD and GFD-treated CeD) increased the expression of the small bowel homing marker CCR9 on autologous responding T-cells (Figure 5D). In a similar 
286 manner, 19-mer primed cDC2 from patients with active CeD decreased CCR9 expression on 287 stimulated T-cells (Figure 5D). The expression of $\beta 7$ integrin or skin homing marker CLA on 288 stimulated T-cells was, however, not affected in any case (Figure 5E, F). 
290 The mononuclear phagocyte system, including DCs, macrophages and monocytes, is of

291 crucial relevance in autoimmune disorders. In CeD, mucosal pDCs and regulatory CD103 ${ }^{+}$ 292 DCs numbers are declined, while active cDCs and macrophages are increased. ${ }^{[20-21]}$ Here we 293 demonstrate that GFD-treated CeD patients display a slight decrease of circulating pDC and 294 CDC1 - which is in agreement with a previous report -, ${ }^{[22 a]}$ while other DC or monocyte subsets 295 are not altered referred to healthy controls. Both circulating DC and monocyte subsets display 296 a gut-homing profile in patients with active CeD. Of note, although such gut-homing profile is 297 characterized by a higher expression of the small-gut-homing CCR9 receptor and reduced 298 expression of skin-homing marker CLA on DC subsets, the gut-homing profile on monocyte 299 subsets is characterized by a higher expression of $\beta 7$ integrin. These differential mechanisms 300 controlling DC and monocyte subsets migration to the intestinal mucosa may help to explain 301 the higher DC and macrophage infiltrate described in the duodenal tissue of patients with active 302 CeD. ${ }^{20 \mathrm{~b}, 21,30]}$ However, additional research is needed to confirm our results since the number 303 of active CeD patients recruited in this study was low.

304 Gluten is known to promote migration and activation of monocytes and MoDC, including the 305 expression of maturation markers HLA-DR, CD40, CD80, CD83, and CD86; and cytokines IL-6, 306 IL-8, IL-10, and TNF- $\alpha .{ }^{[23 b, 31]}$ MoDC have been traditionally considered as CDC2 analogues. 307 However, recent studies have revealed that the phenotype and function of MoDC are different 308 to that of $\mathrm{CDC} 2,{ }^{[24]}$ which questions the conclusions from previous MoDC models. Therefore, 309 our work crucially contributes to understand the specific effects of gliadin-derived peptides on 310 bona fide $\mathrm{CDC} 2$ and the autologous naïve T-cells that they stimulate, hence getting a deeper 311 insight into the specific contribution of these cells towards CeD pathogenesis. Even if cDC2 312 might be less relevant than $\mathrm{CDC} 1$ for $\mathrm{CeD}$, given the decreased number of $\mathrm{cDC} 2$ found in 313 active CeD mucosa, ${ }^{[20 b]}$ we focused our study on these cells due to the scarce presence of 314 cDC1 (less than $0.04 \%$ of PBMCs, which is in agreement with previous reports ${ }^{[32]}$ ). 
315 The peptide 33-mer has been characterized as the most immunodominant peptide for CeD 316 patients due to high affinity for HLA-DQ molecules, especially after deamidation by tissue 317 transglutaminase (TG) $2 .{ }^{[5 c]}$ Indeed, Rakhimova et. al. reported that gluten promoted the 318 expression of maturity markers on MoDC from healthy subjects, regardless of their 319 genotype. ${ }^{[23 a]}$ Consistently, we observed that peptide 33-mer activates cDC2 from both healthy 320 controls and GFD-treated CeD patients. On the other hand, peptides 8-mer and 19-mer 321 exclusively activated cDC2 from GFD-CeD patients, suggesting that their effects may be 322 restricted to CeD patients. It should be noted, however, that none of the peptides affected 323 cDC2 from patients with active disease. One possibility to explain this lack of cDC2 activation 324 is that $\mathrm{CDC} 2$ from active CeD patients are already primed with gut-homing capacity. Thus, they may already display a pro-inflammatory phenotype, reason why the peptides cannot further increase the expression of activation markers. In agreement with this, the cytokine profile of 327 cDC2 was affected by all peptides, preferentially in patients with active CeD - but not with 328 GFD-treated CeD -, suggesting that these cDC2 are ready to respond to peptides when gliadin 329 is present in the mucosa of active CeD patients (i.e. expressing pro-inflammatory cytokines). 330 Interestingly, each gliadin-derived peptide promoted different cytokine profiles on cDC2, being 331 peptide 8-mer the best inducer of a pro-inflammatory Th1/Th17 profile. Nevertheless, despite 332 these effects on cDC2 phenotype and cytokine expression, gliadin-derived peptides were unable to translate the response to autologous naïve T-cells (i.e. cytokine production). Instead, 334 cDC2 primed with the peptide 33-mer efficiently induced CCR9 expression on T-cells. This 335 increased gut-homing imprinting capacity suggests that 33-mer might also contribute to boost 336 T-cell infiltration into the duodenal mucosa, and the subsequent inflammation and tissue 337 remodelling.

338 The inability of immunodominat epitopes to activate mucosal cells has been previously 339 observed, suggesting that a synergistic effect between different peptides might be needed for $340 \mathrm{cDC}$ to promote T-cell activation. ${ }^{[5 b]}$ In their study, Maiuri et. al. found that the immunodominant 341 gliadin epitopes $p \alpha-2$ and $p \alpha-9$ required a previous stimulation with the non-immunodominant 
342 p31-43 in order to induce an adaptive immune response in cultured biopsies from CeD 343 patients. ${ }^{[5 b]}$ Consistently with their observations, we found that the peptide 8-mer induced a 344 pro-inflammatory cytokine expression profile in cDC2, while the immunodominant peptide 33345 mer enhanced the gut-homing capacity of T-cells. Thus, if both peptides were simultaneously 346 used to stimulate $\mathrm{cDC} 2$, they might contribute to develop a complete and functional adaptive 347 T-cell immune response.

348 On the other side, CDC1 and CDC2 process antigens and activates T-cells in different ways. While cDC1 contribute to a CD8+ T-cell driven response, $c D C 2$ efficiently stimulate CD4+ Tcell responses. ${ }^{[33]}$ This, together with a possibly combined antigen presentation of native peptides by other cells (e.g. B-cells), ${ }^{[34]}$ might even induce a greater immune response to gliadin-derived peptides than the response shown here since we could only study the cDC2 outcomes. In addition, recent research has shown a relationship between bacterial proteolytic activity and the infection with reoviruses with an increased sensitivity to dietary antigens such as gluten. ${ }^{[35]}$ Therefore, alternative non-dietary triggers might alter the $\mathrm{DC}$ response and could contribute to strengthen the signal transduction of antigen-presenting cells into T-cells.

In summary, circulating DC and monocyte subsets display a gut-homing profile in CeD patients.

358 Therefore, monitoring peripheral DC and monocyte subsets may be useful, novel biomarkers

359 for the diagnosis of $\mathrm{CeD}$ or the assessment of the compliance to the GFD. Our data also 360 revealed that distinct gliadin-derived peptides elicit differential and complementary effects on 361 cDC2 phenotype and function. Given that CeD patients do not ingest single peptides but a 362 mixed pool of gluten proteins, our results are therefore compatible with a model where different 363 gluten peptides might cooperate independently to the full activation of cDC2 - and possibly 364 other antigen-presenting cells such as CDC1 and B-cells -, and the subsequent promotion of 365 T-cell activation in genetically predisposed individuals with altered microbiota and/or 366 gastrointestinal exposure to reovirus. 


\section{Acknowledgements}

368 This research was finantialy supported by Asociación de Celiacos y Sensibles al Gluten de

369 Madrid (Spain), the Spanish Ministry of Science (RYC-2017-21606) and the Spanish Ministry

370 of Economics and Competitiveness (RTC-2014-2401).

371 Conflict of interests

372 The authors declare no potential conflicts of interest with respect to the research, authorship, 373 and/or publication of this article.

\section{Author contributions}

$375 \mathrm{CEH}, \mathrm{JAG}, \mathrm{DB}$, and EA conceived and designed the experiments. LFS recruited all the patients 376 and obtained the biological samples for the study. CEH, AM and RPA performed the 377 experiments. $\mathrm{CEH}$ and DB contributed to data analysis. Manuscript was drafted by $\mathrm{CEH}$ and 378 DB, and subsequently forwarded to all authors for corrections. EA obtained the funding to 379 develop the study. All authors reviewed and approved the final version of the manuscript. 
380

381

382

383

384

385

386

387

388

389

390

391

392

393

394

395

396

397

398

399

400

401

402

403

404

405

406

\section{References}

[1] a) T. D. Pelkowski, A. J. Viera, Am Fam Physician 2014, 89, 99-105; b) J. Stamnaes, L. M.

Sollid, Semin Immunol 2015, 27, 343-352.

[2] a) A. S. Louka, L. M. Sollid, Tissue Antigens 2003, 61, 105-117; b) L. M. Sollid, B. Jabri, Nat Rev Immunol 2013, 13, 294-302.

[3] T. G. Theethira, M. Dennis, Dig Dis 2015, 33, 175-182.

[4] a) I. Comino, A. Real, L. de Lorenzo, H. Cornell, M. A. Lopez-Casado, F. Barro, P. Lorite,

M. I. Torres, A. Cebolla, C. Sousa, Gut 2011, 60, 915-922; b) P. Koehler, H. Wieser, in:

Gobbetti, M., Gänzle, M. (Eds.), Handbook on Sourdough Biotechnology, Springer Science and Business Media New York 2013, pp. 11-45.

[5] a) L. Shan, O. Molberg, I. Parrot, F. Hausch, F. Filiz, G. M. Gray, L. M. Sollid, C. Khosla, Science 2002, 297, 2275-2279; b) L. Maiuri, C. Ciacci, I. Ricciardelli, L. Vacca, V. Raia, S. Auricchio, J. Picard, M. Osman, S. Quaratino, M. Londei, Lancet 2003, 362, 30-37; c) S. W. Qiao, E. Bergseng, O. Molberg, J. Xia, B. Fleckenstein, C. Khosla, L. M. Sollid, J Immunol 2004, 173, 1757-1762.

[6] A. Camarca, A. Del Mastro, C. Gianfrani, Endocr Metab Immune Disord Drug Targets 2012, $12,207-219$.

[7] S. Vallejo-Diez, D. Bernardo, L. Moreno Mde, A. Munoz-Suano, L. Fernandez-Salazar, C. Calvo, C. Sousa, J. A. Garrote, A. Cebolla, E. Arranz, PLoS One 2013, 8, e80982.

[8] a) S. C. Knight, J. Mertin, A. Stackpoole, J. Clark, Proc Natl Acad Sci U S A 1983, 80, 60326035; b) J. Banchereau, R. M. Steinman, Nature 1998, 392, 245-252.

[9] a) H. Sigmundsdottir, E. C. Butcher, Nat Immunol 2008, 9, 981-987; b) M. A. Travis, D. Sheppard, Annu Rev Immunol 2014, 32, 51-82.

[10] B. Johansson-Lindbom, M. Svensson, O. Pabst, C. Palmqvist, G. Marquez, R. Forster, W. W. Agace, J Exp Med 2005, 202, 1063-1073.

[11] a) A. Rubio-Tapia, I. D. Hill, C. P. Kelly, A. H. Calderwood, J. A. Murray, G. American College of, Am J Gastroenterol 2013, 108, 656-676; quiz 677; b) L. Elli, F. Branchi, R. Sidhu, 
407 S. Guandalini, A. Assiri, F. Rinawi, R. Shamir, P. Das, G. K. Makharia, Expert Rev 408 Gastroenterol Hepatol 2017, 11, 125-138.

409 [12] a) A. J. Stagg, A. L. Hart, S. C. Knight, M. A. Kamm, Gut 2003, 52, 1522-1529; b) F. G. 410 Chirdo, O. R. Millington, H. Beacock-Sharp, A. M. Mowat, Eur J Immunol 2005, 35, 1831-1840; 411 c) T. T. MacDonald, I. Monteleone, M. C. Fantini, G. Monteleone, Gastroenterology 2011, 140, 412 1768-1775; d) A. M. Mowat, Nat Rev Immunol 2018, 18, 405-415.

413 [13] D. Bernardo, M. Chaparro, J. P. Gisbert, Mol Nutr Food Res 2018, 62, e1700931.

414 [14] a) A. M. Mowat, C. C. Bain, J Innate Immun 2011, 3, 550-564; b) E. Zigmond, S. Jung, 415 Trends Immunol 2013, 34, 162-168; c) C. C. Bain, A. M. Mowat, Immunol Rev 2014, 260, 102416117 ; d) T. Joeris, K. Muller-Luda, W. W. Agace, A. M. Mowat, Mucosal Immunol 2017, 10, 845417 864; e) Y. R. Na, M. Stakenborg, S. H. Seok, G. Matteoli, Nat Rev Gastroenterol Hepatol 2019, $418 \quad 16,531-543$.

419 [15] V. Rossini, D. Zhurina, K. Radulovic, C. Manta, P. Walther, C. U. Riedel, J. H. Niess, 420 Mucosal Immunol 2014, 7, 533-548.

421 [16] A. Lahiri, C. Abraham, Gastroenterology 2014, 147, 835-846.

422 [17] A. Bujko, N. Atlasy, O. J. B. Landsverk, L. Richter, S. Yaqub, R. Horneland, O. Oyen, E. 423 M. Aandahl, L. Aabakken, H. G. Stunnenberg, E. S. Baekkevold, F. L. Jahnsen, J Exp Med $4242018,215,441-458$.

425 [18] a) M. Guilliams, F. Ginhoux, C. Jakubzick, S. H. Naik, N. Onai, B. U. Schraml, E. Segura, 426 R. Tussiwand, S. Yona, Nat Rev Immunol 2014, 14, 571-578; b) M. Guilliams, L. van de Laar, 427 Front Immunol 2015, 6, 406; c) D. Sichien, B. N. Lambrecht, M. Guilliams, C. L. Scott, Mucosal 428 Immunol 2017, 10, 831-844; d) M. Embgenbroich, S. Burgdorf, Front Immunol 2018, 9, 1643. 429 [19] J. Hettinger, D. M. Richards, J. Hansson, M. M. Barra, A. C. Joschko, J. Krijgsveld, M. $430 \quad$ Feuerer, Nat Immunol 2013, 14, 821-830.

431 [20] a) M. Raki, A. C. Beitnes, K. E. Lundin, J. Jahnsen, F. L. Jahnsen, L. M. Sollid, Mucosal 432 Immunol 2013, 6, 985-992; b) A. C. Beitnes, M. Raki, K. E. Lundin, J. Jahnsen, L. M. Sollid, F. 433 L. Jahnsen, Scand J Immunol 2011, 74, 186-194; c) D. T. Ruane, E. C. Lavelle, Front Immunol $434 \quad 2011,2,25$. 
435 [21] M. Raki, S. Tollefsen, O. Molberg, K. E. Lundin, L. M. Sollid, F. L. Jahnsen, 436 Gastroenterology 2006, 131, 428-438.

437 [22] a) R. Ciccocioppo, G. Ricci, B. Rovati, I. Pesce, S. Mazzocchi, D. Piancatelli, A. Cagnoni, 438 D. Millimaggi, M. Danova, G. R. Corazza, Clin Exp Immunol 2007, 149, 487-496; b) G. 439 Terrazzano, M. Sica, C. Gianfrani, G. Mazzarella, F. Maurano, B. De Giulio, S. de Saint440 Mezard, D. Zanzi, L. Maiuri, M. Londei, B. Jabri, R. Troncone, S. Auricchio, S. Zappacosta, E. 441 Carbone, J Immunol 2007, 179, 372-381.

442 [23] a) M. Rakhimova, B. Esslinger, A. Schulze-Krebs, E. G. Hahn, D. Schuppan, W. Dieterich, 443 J Clin Immunol 2009, 29, 29-37; b) B. Chladkova, J. Kamanova, L. Palova-Jelinkova, J. Cinova, 444 P. Sebo, L. Tuckova, J Cell Mol Med 2011, 15, 938-948; c) Y. Junker, S. Zeissig, S. J. Kim, D. 445 Barisani, H. Wieser, D. A. Leffler, V. Zevallos, T. A. Libermann, S. Dillon, T. L. Freitag, C. P. 446 Kelly, D. Schuppan, J Exp Med 2012, 209, 2395-2408; d) L. Giordani, T. Del Pinto, O. 447 Vincentini, C. Felli, M. Silano, M. Viora, Exp Cell Res 2014, 321, 248-254.

448 [24] a) A. Benlahrech, S. Duraisingham, D. King, L. Verhagen, G. Rozis, P. Amjadi, T. Ford, 449 P. Kelleher, S. Patterson, J Leukoc Biol 2015, 97, 873-885; b) M. Alcantara-Hernandez, R. 450 Leylek, L. E. Wagar, E. G. Engleman, T. Keler, M. P. Marinkovich, M. M. Davis, G. P. Nolan, $451 \quad$ J. Idoyaga, Immunity 2017, 47, 1037-1050 e1036.

452 [25] a) S. Husby, S. Koletzko, I. R. Korponay-Szabo, M. L. Mearin, A. Phillips, R. Shamir, R. 453 Troncone, K. Giersiepen, D. Branski, C. Catassi, M. Lelgeman, M. Maki, C. Ribes-Koninckx, 454 A. Ventura, K. P. Zimmer, E. W. G. o. C. D. Diagnosis, E. G. Committee, H. European Society 455 for Pediatric Gastroenterology, Nutrition, J Pediatr Gastroenterol Nutr 2012, 54, 136-160; b) J. 456 F. Ludvigsson, J. C. Bai, F. Biagi, T. R. Card, C. Ciacci, P. J. Ciclitira, P. H. Green, M. 457 Hadjivassiliou, A. Holdoway, D. A. van Heel, K. Kaukinen, D. A. Leffler, J. N. Leonard, K. E. 458 Lundin, N. McGough, M. Davidson, J. A. Murray, G. L. Swift, M. M. Walker, F. Zingone, D. S. 459 Sanders, B. S. G. C. D. G. D. Group, G. British Society of, Gut 2014, 63, 1210-1228; c) G. 460 Oberhuber, G. Granditsch, H. Vogelsang, Eur J Gastroenterol Hepatol 1999, 11, 1185-1194. 461 [26] M. Dall, K. Calloe, M. Haupt-Jorgensen, J. Larsen, N. Schmitt, K. Josefsen, K. Buschard, 462 PLoS One 2013, 8, e66474. 
463 [27] J. Ye, G. Coulouris, I. Zaretskaya, I. Cutcutache, S. Rozen, T. L. Madden, BMC 464 Bioinformatics 2012, 13, 134.

465 [28] K. J. Livak, T. D. Schmittgen, Methods 2001, 25, 402-408.

466 [29] A. C. Beitnes, M. Raki, M. Brottveit, K. E. Lundin, F. L. Jahnsen, L. M. Sollid, PLoS One $467 \quad 2012,7$, e33556.

468 [30] I. Comino, T. Suligoj, H. O. Al-Hassi, G. H. Lee, C. Sousa, J. Landy, P. J. Ciclitira, S. C. 469 Knight, D. Bernardo, Rev Esp Enferm Dig 2014, 106, 64-65.

470 [31] a) J. Cinova, L. Palova-Jelinkova, L. E. Smythies, M. Cerna, B. Pecharova, M. Dvorak, P. 471 Fruhauf, H. Tlaskalova-Hogenova, P. D. Smith, L. Tuckova, J Clin Immunol 2007, 27, 201-209; 472 b) L. Palova-Jelinkova, D. Rozkova, B. Pecharova, J. Bartova, A. Sediva, H. Tlaskalova473 Hogenova, R. Spisek, L. Tuckova, J Immunol 2005, 175, 7038-7045.

474 [32] S. L. Jongbloed, A. J. Kassianos, K. J. McDonald, G. J. Clark, X. Ju, C. E. Angel, C. J. 475 Chen, P. R. Dunbar, R. B. Wadley, V. Jeet, A. J. Vulink, D. N. Hart, K. J. Radford, J Exp Med $4762010,207,1247-1260$.

477 [33] a) J. M. den Haan, S. M. Lehar, M. J. Bevan, J Exp Med 2000, 192, 1685-1696; b) D. 478 Dudziak, A. O. Kamphorst, G. F. Heidkamp, V. R. Buchholz, C. Trumpfheller, S. Yamazaki, C. 479 Cheong, K. Liu, H. W. Lee, C. G. Park, R. M. Steinman, M. C. Nussenzweig, Science 2007, $480 \quad 315,107-111$.

481 [34] a) L. S. Hoydahl, L. Richter, R. Frick, O. Snir, K. S. Gunnarsen, O. J. B. Landsverk, R. 482 Iversen, J. R. Jeliazkov, J. J. Gray, E. Bergseng, S. Foss, S. W. Qiao, K. E. A. Lundin, J. 483 Jahnsen, F. L. Jahnsen, I. Sandlie, L. M. Sollid, G. A. Loset, Gastroenterology 2019, 156, 484 1428-1439 e1410; b) B. A. Heesters, C. E. van der Poel, A. Das, M. C. Carroll, Trends Immunol $485 \quad 2016,37,844-854$.

486 [35] a) R. Bouziat, R. Hinterleitner, J. J. Brown, J. E. Stencel-Baerenwald, M. Ikizler, T. Mayassi, 487 M. Meisel, S. M. Kim, V. Discepolo, A. J. Pruijssers, J. D. Ernest, J. A. Iskarpatyoti, L. M. 488 Costes, I. Lawrence, B. A. Palanski, M. Varma, M. A. Zurenski, S. Khomandiak, N. McAllister, 489 P. Aravamudhan, K. W. Boehme, F. Hu, J. N. Samsom, H. C. Reinecker, S. S. Kupfer, S. 490 Guandalini, C. E. Semrad, V. Abadie, C. Khosla, L. B. Barreiro, R. J. Xavier, A. Ng, T. S. 
491 Dermody, B. Jabri, Science 2017, 356, 44-50; b) A. Caminero, J. L. McCarville, H. J. Galipeau, 492 C. Deraison, S. P. Bernier, M. Constante, C. Rolland, M. Meisel, J. A. Murray, X. B. Yu, A. 493 Alaedini, B. K. Coombes, P. Bercik, C. M. Southward, W. Ruf, B. Jabri, F. G. Chirdo, J. 494 Casqueiro, M. G. Surette, N. Vergnolle, E. F. Verdu, Nat Commun 2019, 10, 1198. 


\section{Figure legends}

497 Figure 1: Circulating plasmacytoid dendritic cell (DC) and type 1 conventional DC 498 subsets are slightly decreased in gluten-free diet treated celiac disease patients.

499 A) Human circulating dendritic cells (DC) and monocyte subsets were identified within singlet 500 viable peripheral blood mononuclear cells (PBMC). Plasmacytoid DC ( $p D C)$ were identified as

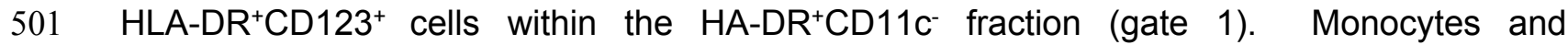
502 conventional DC (cDC) were identified as $\mathrm{HLA}-\mathrm{DR}^{+} \mathrm{CD} 11 \mathrm{c}^{+}$cells (gate 2 ). Monocytes were 503 further divided into classical (CD14+CD16-), non-classical (CD14-CD16 $\left.{ }^{+}\right)$and intermediate $504\left(\mathrm{CD} 14^{+} \mathrm{CD} 16^{+}\right)$monocytes (gate 2). $\mathrm{CDC}$ were identified within the CD14-CD16- fraction (gate $5053)$ as $\mathrm{CDC} 1\left(\mathrm{CD} 141^{+}\right)$and $\mathrm{CDC} 2\left(\mathrm{CD} 1 \mathrm{C}^{+}\right)$. Data are shown as percentage of gated cells. B-G) 506 Pooled results, determined as percentage within singlet PBMC, from healthy controls, patients 507 with active celiac disease (aCeD), and gluten-free diet treated (GFD)-CeD are shown for pDC 508 (B), cDC1 (C), cDC2 (D), and classical monocytes (E), non-classical monocytes (F), and 509 intermediate monocytes (G). Data are represented as mean \pm SD. One-way ANOVA was 510 applied. Ad-hoc comparisons were, in all cases, compared with the healthy controls. P-values $511<0.05$ were considered significant.

512 Figure 2: Circulating dendritic cells and monocytes display a gut-homing profile in 513 celiac disease.

514 A) Dendritic cell (DC) and monocyte subsets were identified as in Figure $1 \mathrm{~A}$, and analysed for 515 the expression of CLA as in the example, as well as $\beta 7$ and CCR9 (not shown). The percentage 516 of positive cells was determined by the fluorescence minus one (FMO) method. B-G) Pooled 517 results of positive cells for each marker within each cell type from healthy controls, patients 518 with active celiac disease (aCeD), and gluten-free diet treated (GFD)-CeD are shown for 519 plasmacytoid DC (pDC, B), type 1 conventional DC (cDC1, C), type 2 conventional DC (cDC2, 520 D), classical monocytes (cl.Mo, E), non-classical monocytes (non-cl.Mo, F) and intermediate 
521 monocytes (int.Mo, G). Data are shown as mean \pm SD of the percentage of positive cells. One522 way ANOVA was applied. Differences relative to Hc samples are shown as * $p<0.1$; and 523 differences relative to aCeD samples are shown as \# $p<0.1$ and \#\# $p<0.05$.

524 Figure 3: Gliadin-derived peptides induce maturation in type 2 conventional dendritic cells from gluten-free diet treated celiac disease patients.

526 Type 2 conventional dendritic cells (cDC2) from healthy controls, patients with active celiac disease (active $\mathrm{CeD}$ ) and patients with gluten-free diet treated (GFD)-CeD were challenged ex vivo with gliadin-derived 33-mer, 8-mer and 19-mer peptides. Cells cultured in resting conditions acted as internal negative controls (C). Percentage of positive cells for each marker was determined as in Figure 2A. Pooled results for the expression of CD40 (A), CD80 (B), CD83 (C), and CD86 (D) are shown. Data are shown as mean \pm SD of the percentage of positive cells. Paired t-test was applied within each patient group referred to the culture in resting conditions. P-values $<0.05$ were considered significant $\left({ }^{*} p<0.05\right)$.

Figure 4: Peptide 8-mer induces a Th1/Th17 cytokine profile on type 2 conventional dendritic cells from active celiac disease patients.

Heatmap displaying cytokine gene expression changes in type 2 conventional dendritic cells from healthy controls, patients with active and gluten-free diet treated (GFD) (C) celiac disease (CeD) after in vitro-priming with peptides 33-mer, 8-mer, and 19-mer (A-C). Results are referred to those obtained from resting conditions for each patient group. Data are displayed as mean $\log _{2}$-transformed fold-changes of the $-\Delta \Delta$ Ct values, with $G A D P H$ as housekeeping control. Paired t-test was applied within each patient group referred to the culture in resting conditions.

Figure 5: Type 2 conventional dendritic cells primed with the peptide 33-mer induce a gut-homing profile on responding T-cells. 
545 Type 2 conventional dendritic cells (cDC2) from healthy controls or patients with active or 546 gluten-free diet (GFD)-treated celiac disease (CeD) were cultured in resting conditions (C) or 547 in the presence of gliadin-derived peptides 33-mer (33m), 8-mer (8m) or 19-mer (19m). cDC2 548 were subsequently used to stimulate autologous T-cells. The percentage of positive T-cells for 549 the expression of intracellular cytokines IFN- $\gamma(A), I L-17 A(B)$, and IL-10 (C), and the surface 550 homing markers CCR9 (D), $\beta 7$ integrin (E), and CLA (F) were determined. Data are shown as 551 mean $\pm S D$ of the percentage of positive cells. Paired t-test was applied within each patient 552 group referred to the culture in resting conditions. P-values $<0.05$ were considered significant $553 \quad\left({ }^{*} p<0.05\right.$, and $\left.{ }^{* * *} p<0.001\right)$ 


\section{Tables}

Table 1 Clinical and demographic characteristics of CeD patients and controls

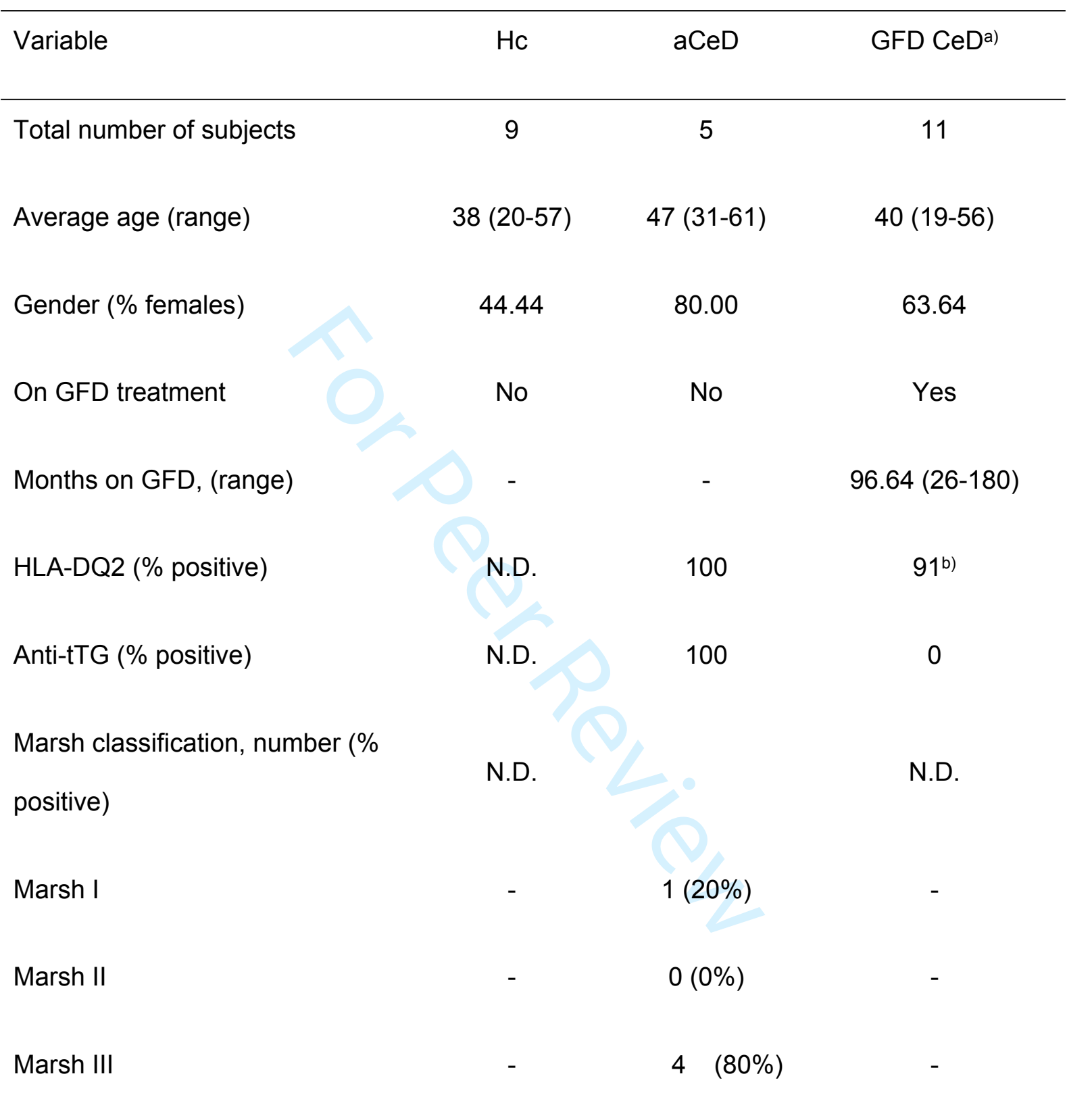

a) GFD CeD patients were diagnosed after positive genetics, serology, and villous atrophy according to pathological analysis. After following a GFD, patients achieved mucosal healing and negative serology values of anti-tTG. b) Data was not available for one patient. 
CeD, celiac disease; GFD, gluten-free diet; Hc, healthy controls; N.D., not determined; tTG, tissue transglutaminase. 


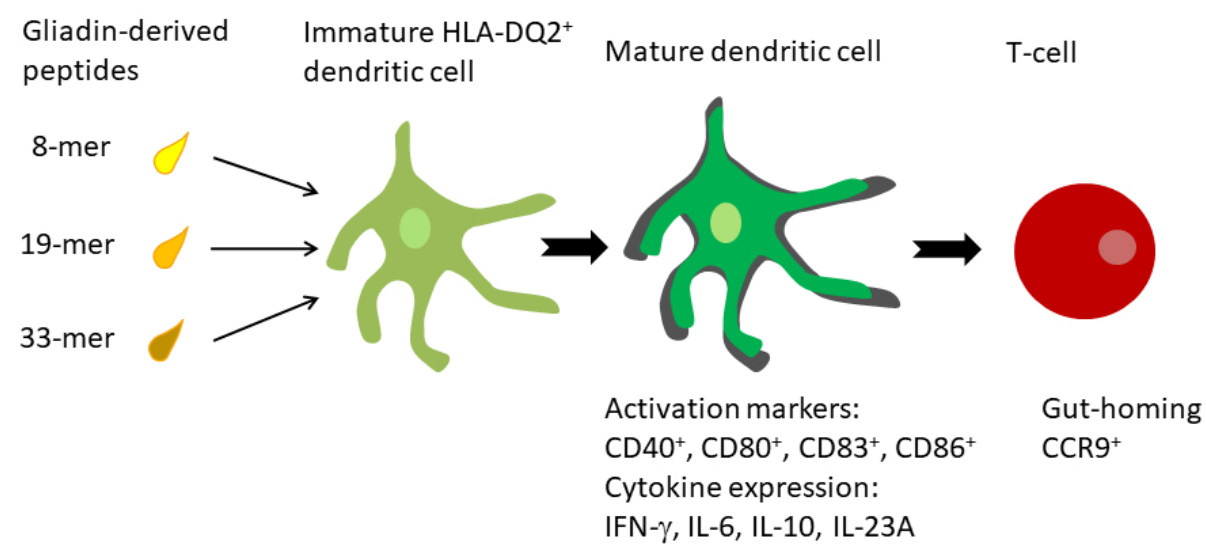

Gliadin-derived peptides (i.e. 8-mer, 19-mer, 33-mer) might cooperate to promote full dendritic cell activation to develop a subsequent $\mathrm{T}$-cell response in genetically predisposed individuals (HLA-DQ2 ${ }^{+}$)

$254 \times 190 \mathrm{~mm}(96 \times 96 \mathrm{DPI})$ 


\section{Graphical abstract text}

Gliadin-derived peptides (i.e. 8-mer, 19-mer, 33-mer) might cooperate to promote full dendritic cell activation to develop a subsequent T-cell response in genetically predisposed individuals $\left(\mathrm{HLA}^{-\mathrm{DQ} 2^{+}}\right)$ 


\section{Figure 1}
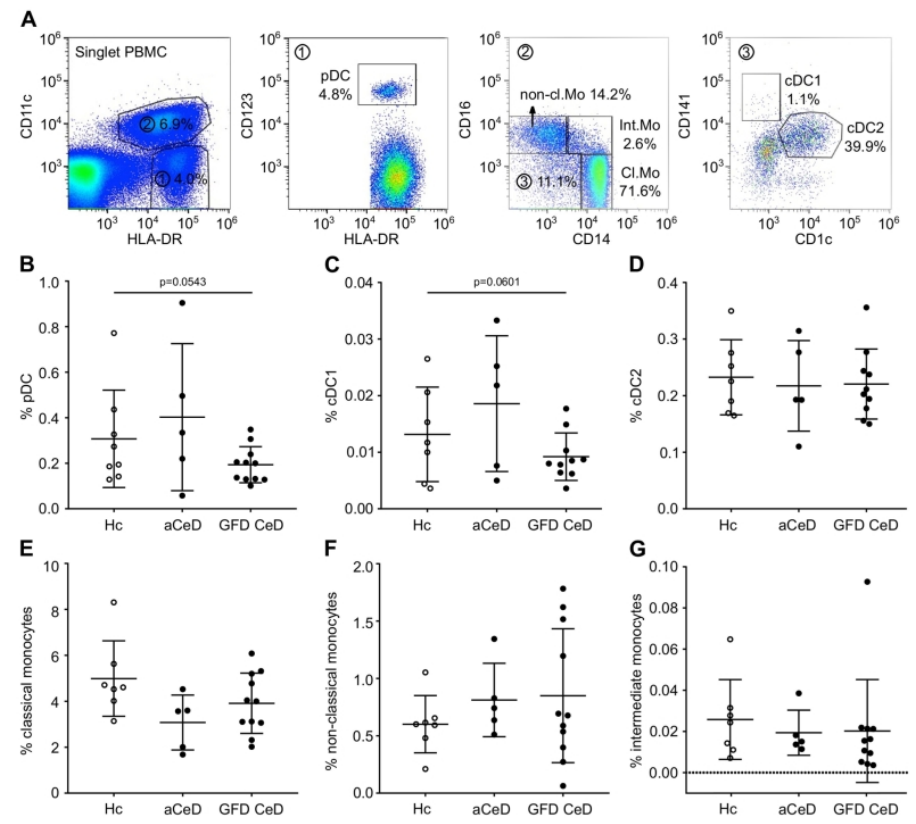

Figure 1: Circulating plasmacytoid dendritic cell (DC) and type 1 conventional DC subsets are slightly decreased in gluten-free diet treated celiac disease patients.

$$
210 \times 297 \mathrm{~mm} \text { ( } 300 \times 300 \text { DPI) }
$$




\section{Figure 2}
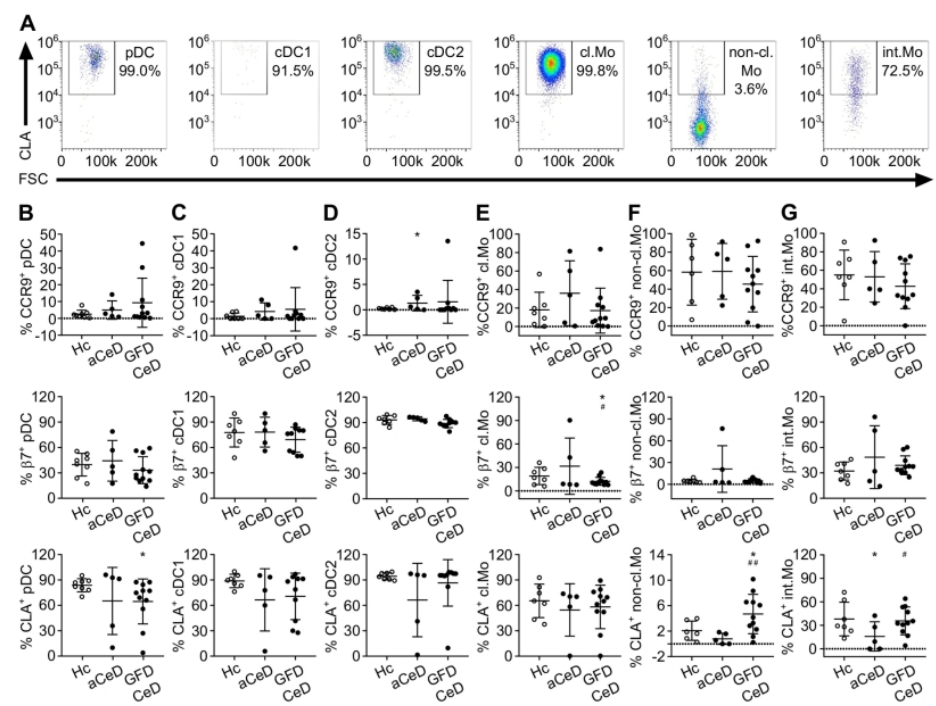

Figure 2: Circulating dendritic cells and monocytes display a gut-homing profile in celiac disease.

$$
210 \times 297 \mathrm{~mm}(300 \times 300 \text { DPI) }
$$




\section{Figure 3}

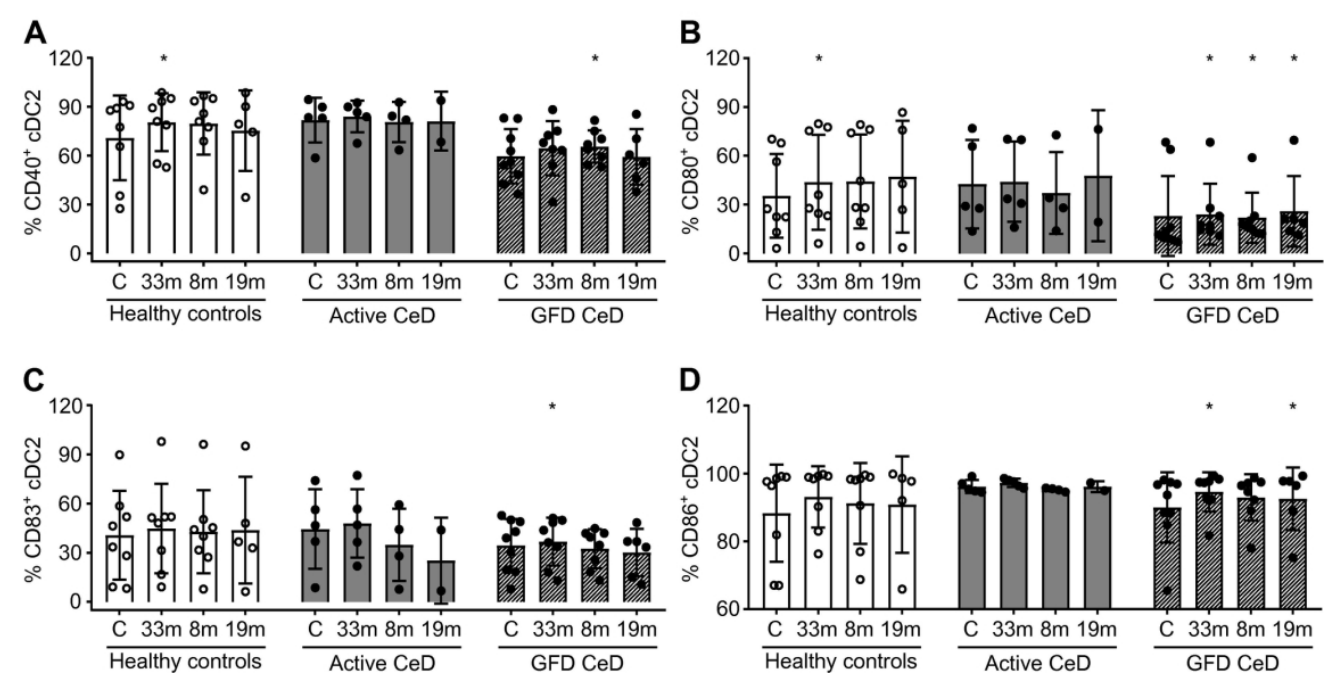

Figure 3: Gliadin-derived peptides induce maturation in type 2 conventional dendritic cells from gluten-free diet treated celiac disease patients.

$172 \times 98 \mathrm{~mm}(300 \times 300 \mathrm{DPI})$ 


\section{Figure 4}

A

\begin{tabular}{l|ccc|}
\multicolumn{4}{l}{ A Healthy controls } \\
\cline { 2 - 4 } & $33 \mathrm{~m}$ & $8 \mathrm{~m}$ & $19 \mathrm{~m}$ \\
\cline { 2 - 4 } IFNG & 0.4564 & -0.1236 & 0.8380 \\
TGFB & -0.5406 & -0.4888 & -0.3870 \\
TNFA & 0.4369 & 0.1088 & 0.0950 \\
IL6 & 1.0163 & 0.0400 & 0.9730 \\
IL10 & -0.0131 & -0.2200 & -0.5910 \\
IL23A & 1.0194 & 0.3225 & 0.3800 \\
\hline
\end{tabular}

\begin{tabular}{l|ccc|}
\multicolumn{3}{l}{ B } & \multicolumn{3}{c}{ Active CeD } \\
\cline { 2 - 4 } & $33 \mathrm{~m}$ & $8 \mathrm{~m}$ & $19 \mathrm{~m}$ \\
\cline { 2 - 4 } IFNG & -0.0450 & 1.2317 & 1.8450 \\
TGFB & -0.0030 & 0.1188 & 0.3800 \\
TNFA & 0.0640 & 0.2163 & 0.0000 \\
IL6 & 3.8380 & 4.4800 & 0.4500 \\
IL10 & -0.6850 & 0.5150 & -0.2150 \\
\hline IL23A & -0.1300 & 1.0725 & -2.9450 \\
\cline { 2 - 4 } & & &
\end{tabular}

\begin{tabular}{|c|c|c|c|c|}
\hline \multirow[t]{2}{*}{ C } & \multicolumn{3}{|c|}{ GFD CeD } & \multirow{8}{*}{ 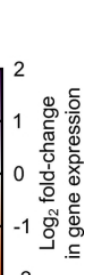 } \\
\hline & $33 m$ & $8 m$ & $19 m$ & \\
\hline IFNG & -2.8100 & -1.6357 & -0.2360 & \\
\hline TGFB & 0.5612 & 0.6481 & 0.9217 & \\
\hline TNFA & 0.6737 & 0.4881 & 0.6050 & \\
\hline IL6 & 0.1729 & 0.0521 & -1.3575 & \\
\hline IL10 & -0.8500 & -0.7483 & -1.2925 & \\
\hline IL23A & -1.0840 & -0.1683 & -1.3050 & \\
\hline
\end{tabular}

Figure 4: Peptide 8-mer induces a Th1/Th17 cytokine profile on type 2 conventional dendritic cells from active celiac disease patients.

$179 \times 52 \mathrm{~mm}(300 \times 300 \mathrm{DPI})$ 


\section{Figure 5}
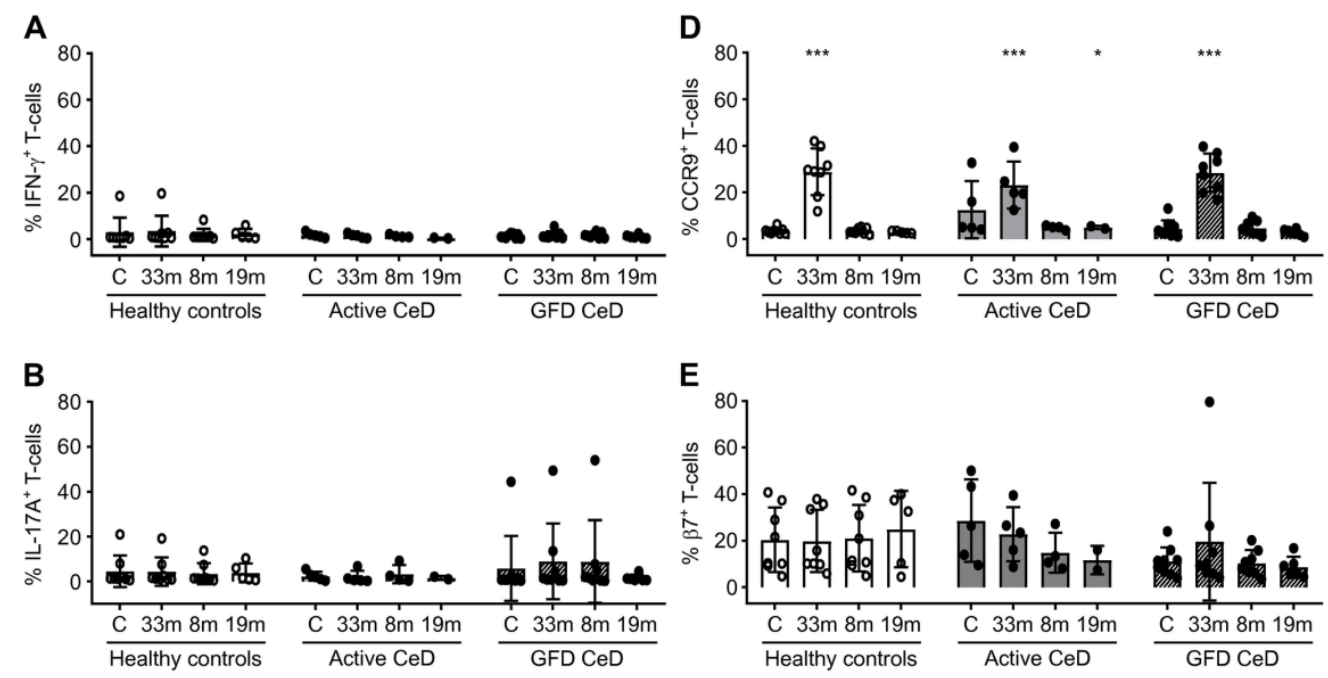

E
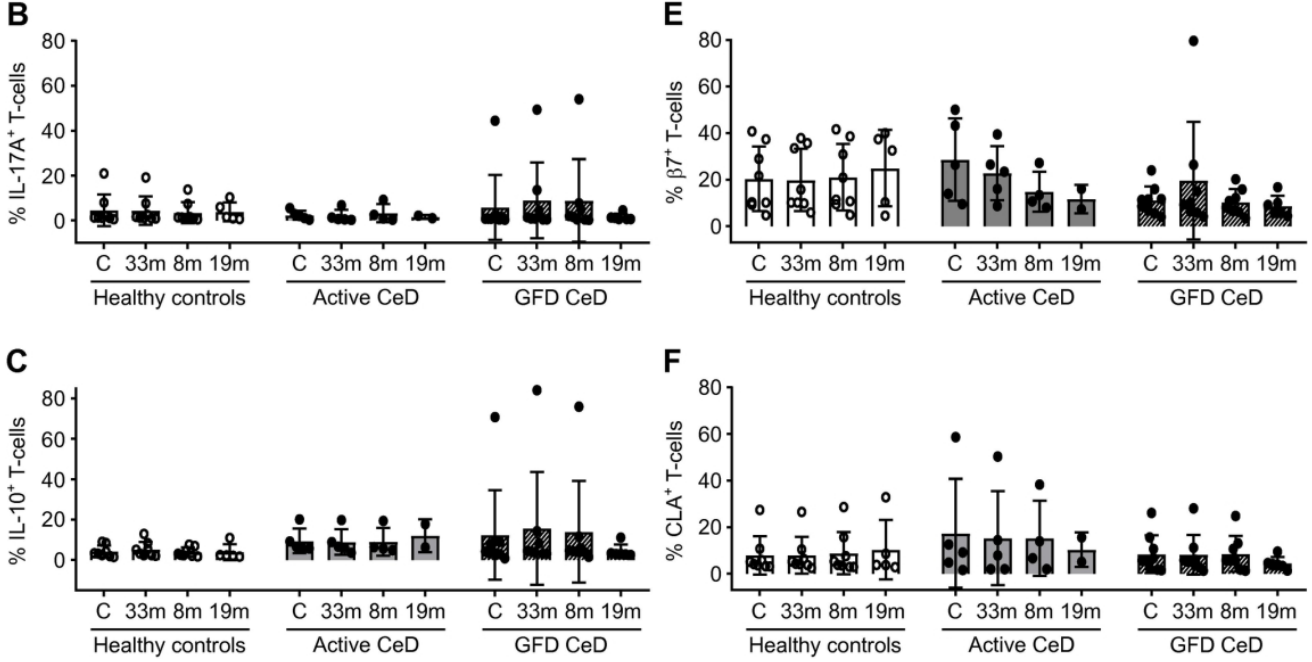

Figure 5: Type 2 conventional dendritic cells primed with the peptide 33-mer induce a gut-homing profile on responding T-cells.

$172 \times 144 \mathrm{~mm}(300 \times 300 \mathrm{DPI})$ 


\section{Supplementary figure 1}

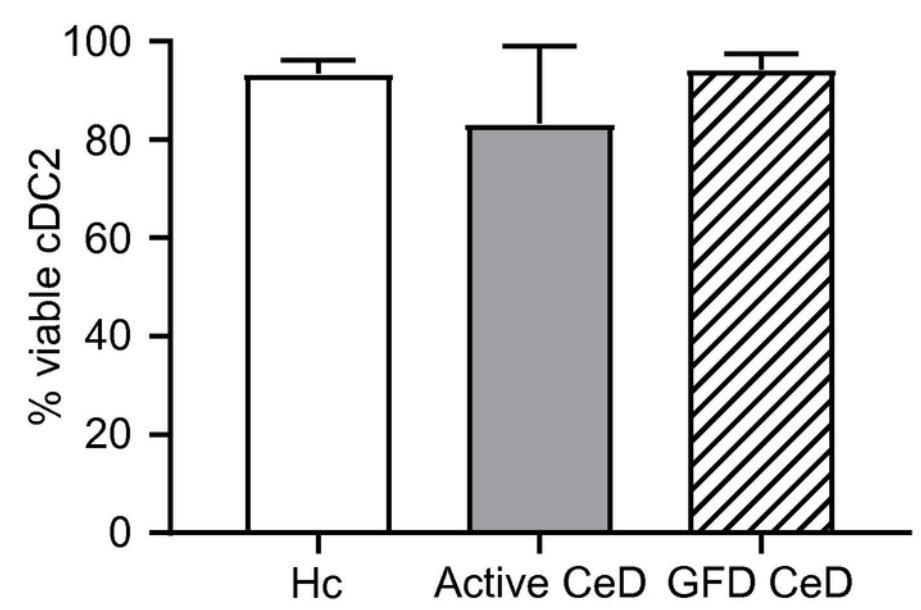

Supplementary figure 1: Purity of viable type 2 conventional dendritic cells after magnetic cell isolation.

$86 \times 53 \mathrm{~mm}(300 \times 300 \mathrm{DPI})$ 


\section{Supplementary figure 2}

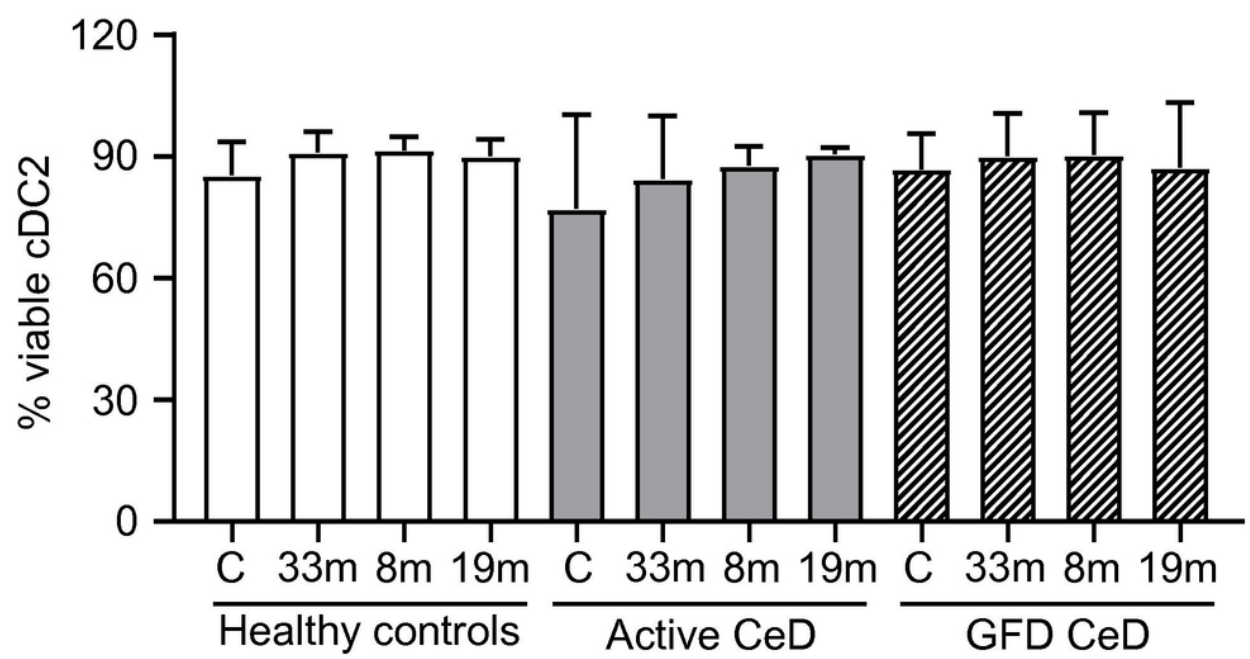

Supplementary figure 2: Gliadin-derived peptides do not alter type 2 conventional dendritic cell viability following in vitro challenge.

$87 \times 58 \mathrm{~mm}(300 \times 300 \mathrm{DPI})$ 


\section{Supplementary figure 3}
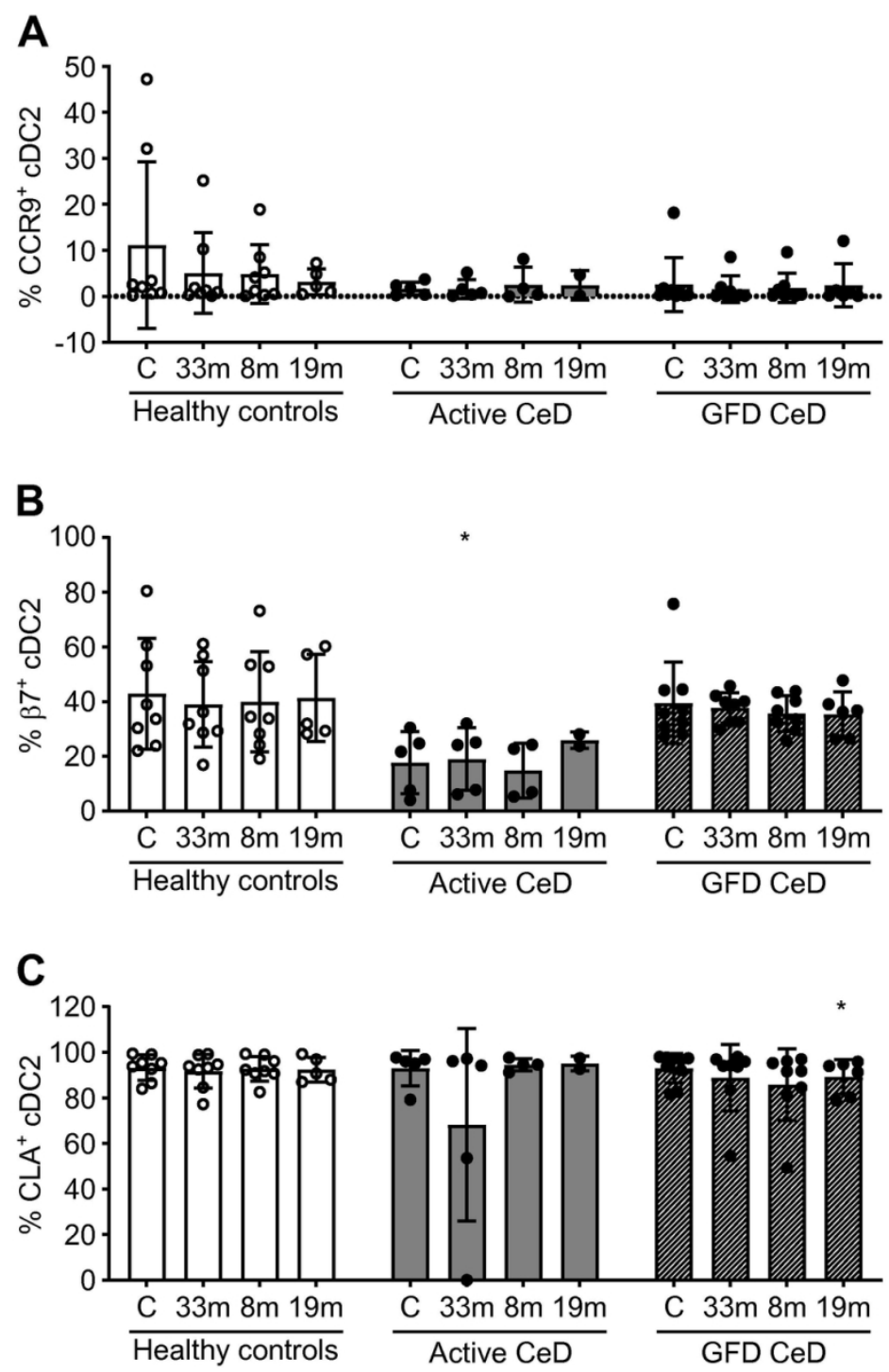

Supplementary figure 3: Gliadin-derived peptides do not modify type 2 conventional dendritic cells homing profile.

$87 \times 144 \mathrm{~mm}(300 \times 300$ DPI $)$ 